\title{
IN SITU OXYGEN ISOTOPE COMPOSITIONS IN OLIVINES OF DIFFERENT TYPES OF COSMIC SPHERULES: AN ASSESSMENT OF RELATIONSHIPS TO CHONDRITIC PARTICLES
}

\section{DOI:}

10.1016/j.gca.2016.08.024

\section{Document Version}

Accepted author manuscript

Link to publication record in Manchester Research Explorer

\section{Citation for published version (APA):}

Rudraswami, N. G., Prasad, M. S., Jones, R., \& Nagashima, K. (2016). IN SITU OXYGEN ISOTOPE COMPOSITIONS IN OLIVINES OF DIFFERENT TYPES OF COSMIC SPHERULES: AN ASSESSMENT OF RELATIONSHIPS TO CHONDRITIC PARTICLES. Geochimica et Cosmochimica Acta.

https://doi.org/10.1016/j.gca.2016.08.024

\section{Published in:}

Geochimica et Cosmochimica Acta

\section{Citing this paper}

Please note that where the full-text provided on Manchester Research Explorer is the Author Accepted Manuscript or Proof version this may differ from the final Published version. If citing, it is advised that you check and use the publisher's definitive version.

\section{General rights}

Copyright and moral rights for the publications made accessible in the Research Explorer are retained by the authors and/or other copyright owners and it is a condition of accessing publications that users recognise and abide by the legal requirements associated with these rights.

\section{Takedown policy}

If you believe that this document breaches copyright please refer to the University of Manchester's Takedown Procedures [http://man.ac.uk/04Y6Bo] or contact uml.scholarlycommunications@manchester.ac.uk providing relevant details, so we can investigate your claim.

\section{OPEN ACCESS}




\section{Abstract}

Cosmic spherules collected from deep sea sediments of the Indian Ocean having different textures such as scoriaceous (4), relict-bearing (16), porphyritic (35) and barred olivine (2) were investigated for petrography, as well as high precision oxygen isotopic studies on olivine grains using secondary ion mass spectrometry (SIMS). The oxide $\mathrm{FeO} / \mathrm{MgO}$ ratios of large olivines $(>20 \mu \mathrm{m})$ in cosmic spherules have low values similar to those seen in the olivines of carbonaceous chondrite chondrules, rather than matching the compositions of matrix. The oxygen isotope compositions of olivines in cosmic spherules have a wide range of $\delta^{18} \mathrm{O}, \delta^{17} \mathrm{O}$ and $\Delta^{17} \mathrm{O}$ values as follows: -9 to $40 \%$, -13 to $22 \%$ and -11 to $6 \%$. Our results suggest that the oxygen isotope compositions of the scoriaceous, relictbearing, porphyritic and barred spherules show provenance related to the carbonaceous $(\mathrm{CM}$, $\mathrm{CV}, \mathrm{CO}$ and $\mathrm{CR}$ ) chondrites. The different types of spherules that has experienced varied atmospheric heating during entry has not significantly altered the $\Delta^{17} \mathrm{O}$ values. However, one of the relict-bearing spherules with a large relict grain has $\Delta^{17} \mathrm{O}=5.7 \%$, suggesting that it is derived from ${ }^{16} \mathrm{O}$-poor material that is not recognized in the meteorite record. A majority of the spherules have $\Delta^{17} \mathrm{O}$ ranging from -4 to $-2 \%$, similar to values in chondrules from carbonaceous chondrites, signifying that chondrules of carbonaceous chondrites are the major contributors to the flux of micrometeorites, with an insignificant fraction derived from ordinary chondrites. Furthermore, barred spherule data shows that during atmospheric entry an increase in $\sim 10 \%$ of $\delta^{18} \mathrm{O}$ value surges $\Delta^{17} \mathrm{O}$ value by $\sim 1 \%$. 
The Earth is continuously bombarded by an extra-terrestrial material flux of $\sim 30,000$ tons per annum (Love and Brownlee, 1991). While more than $90 \%$ of this material gets evaporated in the atmosphere, a fraction of the colliding particles survive atmospheric entry heating to reach the Earth's surface (Taylor et al., 1998; Yada et al., 2004; Plane, 2012; Prasad et al., 2013). The survivability of these particles that penetrate the Earth's atmosphere depends on various factors such as mass, density, velocity, zenith angle during entry and chemical compositions that are markedly different for different precursors (Love and Brownlee, 1991, 1993; Rudraswami et al., 2015a). The micrometeorites that have entered Earth's atmosphere at high zenith angle and low velocity are interesting because their petrologic and isotopic characteristics are largely preserved thereby providing constraints on the parent body they have originated from. However, those micrometeorite particles that enter at low zenith angle and high velocity experience large heating and vaporization during entry, thereby altering the chemical and isotopic compositions. Under such circumstances, relating the chemical composition of the micrometeorites/cosmic spherules to their origins is marred by uncertainties (Kurat et al. 1994, Beckerling and Bischoff 1995, Brownlee et al. 1997, Greshake et al. 1998; Cordier et al., 2011; Rudraswami et al., 2012). unravel the complexity involved in distinguishing the known components of micrometeorites and their parent bodies. For carbonaceous chondrites, the oxygen isotope compositions of the chondrules, CAIs and matrix fall close to the Carbonaceous Chondrite Anhydrous Minerals (CCAM) line with slope $~ 1$ (Clayton et al., 1993). Mixing of these different components with nebular gas, and parent-body processing after accretion, led to changes in $\delta^{18} \mathrm{O}$ and $\Delta^{17} \mathrm{O}$ values (Yurimoto et al., 2008). However, the chondrules in ordinary chondrites have a 
different trend than carbonaceous chondrites and fall above the CCAM line (Clayton et al., 1991; Kita et al., 2010). For cosmic spherules, interactions with the terrestrial atmosphere during atmospheric entry without substantial evaporative mass loss do not alter the $\Delta^{17} \mathrm{O}$, but can change the $\delta^{18} \mathrm{O}$ value significantly (Engrand et al., 2005; Suavet et al., 2010; Rudraswami et al., 2015b). Despite the effects of atmospheric mixing, some cosmic spherules retain relict grains that preserve their primary oxygen isotope signatures, indicating that they did not crystallize from a melt during atmospheric entry (Engrand et al., 2005; Yada et al., 2005; Genge et al., 2008; Suavet et al., 2010; Rudraswami et al., 2015b). One of the issues we wish to address here is whether exchange of $\delta^{17,18} \mathrm{O}$ between a micrometeorite and the atmosphere will preclude an understanding of its parent body. In an earlier study, we showed that most Mg-rich relict olivine grains of cosmic spherules have $\Delta{ }^{17} \mathrm{O}$ ranging from -5 to $0 \%$, thereby suggesting that chondrules of carbonaceous chondrites could be the origin for the relict bearing cosmic spherules (Rudraswami et al., 2015b). In addition, some $\mathrm{Mg}$-rich relict olivine grains are very ${ }^{16} \mathrm{O}$-rich, with $\Delta^{17} \mathrm{O}$ ranging from -21.9 to $-18.7 \%$, similar to oxygen isotopic compositions observed in calcium aluminium rich inclusions (CAIs), amoeboid olivine aggregates (AOAs), and some porphyritic chondrules from carbonaceous chondrites (Rudraswami et al., 2015b). Earlier studies were done on large sized relict bearing cosmic spherules largely dominated by forsteritic olivine. In the present study, we have performed high precision ion microprobe oxygen isotope analyses of olivines in 57 cosmic spherules having different textures (scoriaceous, relict-bearing, porphyritic and 94 barred) that has experienced different heating (i.e. partially to large scale heating) during atmospheric entry. The objectives is to see the oxygen isotope variation in different type of cosmic spherules and compare with different chondrites and their components. This will

97 benefit in recognizing and probably quantifying the range of contributors to the 98 micrometeorite flux on the Earth. Secondly, the particle as it enter the stratosphere undergo 

and barred olivine (2).

oxygen isotopic modification leading to enrichment of $\delta^{17,18} \mathrm{O}$. Distinguishing the variations in $\delta^{17,18} \mathrm{O}$ and $\Delta^{17} \mathrm{O}$ will be beneficial to identify the parent bodies of these particles.

\section{SAMPLE SELECTION}

sea sediments of the Indian Ocean from a seafloor depth of $~ 5000 \mathrm{~m}$. A grab sampler of size $50 \times 50 \mathrm{~cm}$ (length $\times$ breadth) has been used to sample the seafloor sediments: the sampler penetrates to a depth of $\sim 15 \mathrm{~cm}$ and has the capacity to pick up $\sim 45 \mathrm{~kg}$ of wet sediments (Rudraswami et al., 2011a; Rudraswami et al. 2012; Prasad et al., 2013). The sediments were sieved using a $200 \mu \mathrm{m}$ mesh sized sieve and the $>200 \mu \mathrm{m}$ portions were dried and subjected to magnetic separation. Individual spherules were handpicked under a binocular microscope from these magnetic separates. A total of $\sim 2500$ spherules were mounted in 12 sections which were carefully ground and polished to expose the internal textures. Fifty seven cosmic spherules of different types, have experienced different stages of heating during entry and that have large olivine grain $(>20 \mu \mathrm{m})$, were selected for oxygen isotope studies from the total 2500 observed under scanning electron microscope (SEM). We focus on olivine oxygen isotope studies in different micrometeorites as a fairly robust indicator to understand precursor meteorite body, and different level of heating in different types of cosmic spherules will provide information on stratospheric oxygen isotope exchange during interaction. The selection criteria for spherules was to sample a representative selection of different petrographic textures and types such as scoriaceous (4), relict-bearing (16), porphyritic (35)

\section{ANALYTICAL TECHNIQUES}


A JEOL JSM 5800LV SEM having an OXFORD INCA energy dispersive spectrometer detector (EDS,ISIS-300 at National Institute of Oceanography, Goa) was used to observe high resolution back scattered electron images (BSE) for classifying the spherules.

128 The images were used to select the best spherules and identify phases for chemical and 129 oxygen isotope analyses using electron microprobe and ion microprobe, respectively. A

130 Cameca SX5 Electron Micro Probe Analyzer (EPMA at National Institute of Oceanography,

131 Goa) equipped with four spectrometers was used to determine the elemental composition of

132 different phases in the spherules, and the operating conditions are identical to those used in

133 Rudraswami et al. (2015b). After SEM and EPMA analyses, we selected 57 cosmic spherules

134 having olivines with grain sizes $>20 \mu \mathrm{m}$ for further oxygen three isotope studies based on morphological features and the grain sizes.

Oxygen three isotope analyses on cosmic spherules were performed using the

137 Secondary Ion Mass Spectrometer (SIMS, Cameca IMS 1280 at University of Hawaii, USA).

138 The $\mathrm{Cs}^{+}$primary beam ion current $\sim 1 \mathrm{nA}$ was rastered over $7 \times 7 \mu \mathrm{m}$ on the selected phase

139 for measuring secondary ions. The mass resolving power $(\mathrm{M} / \Delta \mathrm{M})$ used for ${ }^{16} \mathrm{O}^{-}$and ${ }^{18} \mathrm{O}^{-}$was

140 2000. Higher mass resolving power of $\sim 5600$ was used for ${ }^{17} \mathrm{O}^{-}$to resolve the contribution

141 of ${ }^{16} \mathrm{OH}^{-}$. The instrument mass fractionation was corrected using San Carlos olivine as the

142 running standard. Analyses that deviated from the selected spots, and which overlap

143 inclusions, cracks or grain boundaries, are excluded from the study. Detailed analytical

144 conditions were similar to those used by Rudraswami et al. (2015b). 

analyses using ion microprobe are shown in Fig. 1. Appendix A provides 57 BSE images of all the cosmic spherules studied for oxygen isotopic composition. Although many spherules contain large grains, the presence of relict grains in spherules is not very common. Relict minerals, as defined here, can be distinguished from secondary crystallized grains (minerals that crystallized rapidly subsequent to atmospheric melting) by their grain size, morphology, Mg-rich composition and/or presence of pure Fe,Ni-metal inclusions (Genge et al., 2008). The chemical compositions and the oxygen three isotope analyses of the olivine grains are provided in Appendix B and Table 1, respectively. Four scoriaceous spherules namely, AAS62-61-P64, AAS62-9-P43, AAS62-9-P51 and AAS62-9-P54 were identified for oxygen isotope studies (Fig. 1a,b and Appendix A). These spherules contain rare relict grains which are $\mathrm{Mg}$ rich with Fo content ranging from 98 to 99\%, except in the case of AAS62-9-P54 which has low Fo content (Appendix B and Table 1). The spread in oxygen isotope compositions in the relict olivine grains from scoriaceous spherules is as follows: $\delta^{17} \mathrm{O} \sim-12.4$ to $7.9 \%$, $\delta^{18} \mathrm{O} \sim-2.4$ to $19.4 \%$ and $\Delta^{17} \mathrm{O} \sim$ -11.2 to $-2.2 \%$ (Fig. 2a and Table 1). Two olivine grains with Fo contents of $\sim 99$ and 49 in AAS62-9-P51 and AAS62-9-P54, respectively, fall close to CCAM (Carbonaceous Chondrite Anhydrous Mineral) line, while the one in AAS62-61-P64 is displaced to the right side of the CCAM line (Fig. 2a). The olivine grain in AAS62-9-P43 has an isotopic composition that is close to TF (Terrestrial Fractionation) line and approaching the stratospheric oxygen isotope composition of $\delta^{18} \mathrm{O}=23.5 \%, \delta^{17} \mathrm{O}=11.8 \%$ (Thiemens et al., 1995: Fig. 2a and Table 1). groundmass of small grains. Sixteen relict-bearing cosmic spherules were identified based on the presence of Mg-rich and large size grains (Figs. 1c,d and Appendix A, B). The relict grain bearing spherules have oxygen isotope compositions with $\delta^{17} \mathrm{O}, \delta^{18} \mathrm{O}$ and $\Delta^{17} \mathrm{O}$ as follows: 
$173-10.6$ to $11.3 \%$, -8.5 to $23.7 \%$ and -9.9 to $5.7 \%$, respectively (Fig. 2 b, Table 1 ). Four 174 spherules, AAS38-169-P59, AAS38-203-P67, AAS62-51-P24 and AAS38-207-P42, have

175 single grains that are much larger and visually dominate the whole spherule (Appendix A).

176 The relict olivine grain in AAS38-169-P59 has an oxygen isotope composition that falls

177 above the TF line, $\Delta^{17} \mathrm{O}=5.7 \%$ (Fig. 3a). AAS38-203-P67 contains several relict olivines

178 (Appendix A) with similar forsterite contents ( $99 \%)$ which contain small Fe-Ni inclusions.

179 The oxygen isotope compositions of olivine grains in spherule AAS38-203-P67 are very 180 uniform and mostly lie between the CCAM and TF line (Fig. 3b). AAS62-51-P24 (Appendix

181 A) has a single large forsterite grain (Fo 95\%) with homogeneous chemical composition except for a more FeO-rich overgrowth at the edge, which is the result of heating during atmospheric entry. Such spherules are rare and the oxygen isotope composition of this spherule, based on two analyses, seems to be uniform with $\Delta^{17} \mathrm{O} \sim-0.4 \%$. The data fall on the TF line (Fig. 3c). The two analyses in the relict grain of AAS38-207-P42 fall on the CCAM line $\left(\Delta^{17} \mathrm{O}\right.$ is -2.8 and $-3.3 \%$ ), with $\delta^{18} \mathrm{O}$ of 1.9 and $2.1 \%$, respectively, but one analysis closer to the boundary of the grain shows a high $\delta^{17,18} \mathrm{O}$ value $\left(\delta^{18} \mathrm{O}=22 \%\right.$ ) although $\Delta^{17} \mathrm{O}(-3.3 \%$ o) is identical to the other two analyses (Figs. 3d, Appendix A). were selected for oxygen isotope studies (Fig. 1e,f; Appendix A, B). The presence of zoning in the relict grains of the spherules indicates that heating has not completely altered their chemical properties, and that the original oxygen isotopic compositions, may have been preserved. Oxygen isotope compositions in olivine grains of porphyritic spherules show a

194 wide spread with $\delta^{18} \mathrm{O}$ from -9 to $40 \%$, $\delta^{17} \mathrm{O}$ from -12 to $22 \%$, and $\Delta^{17} \mathrm{O}$ lying between -11

195 to $-2 \%$ (Fig. 2c, Table 1). The distribution of many of the analyses is parallel to, but below, 196 the TF line. 

is difficult to make ion microprobe spot analyses on them. In the absence of wide bars of olivine, bulk oxygen isotope analyses of barred olivine spherules are usually reported using 200 ion microprobe (Engrand et al., 2005; Yada et al., 2005). Here we have identified two barred spherules with large size olivine bars that are uncommon, on which we were able to obtain ion microprobe analyses (Fig. $1 \mathrm{~g}, \mathrm{~h}$ ). Individual $\delta^{18} \mathrm{O}$ values vary from 21 to $30 \%$, $\delta^{17} \mathrm{O}$ varies from 6 to $12 \%$ with $\Delta^{17} \mathrm{O}$ lying between -7 to $-3 \%$ (Fig. 2 d, Table 1 ).

\section{DISCUSSION}

\subsection{OLIVINE IN COSMIC SPHERULES AND ITS RELATION TO CHONDRITES}

Olivine is a common mineral in both carbonaceous $(\mathrm{C})$ and ordinary $(\mathrm{O})$ chondrites. It has a wide range of compositions in the major chondritic components, chondrules and matrix, that vary widely in their relative proportions among different chondrite groups (Brearley and Jones, 1998). Both O and C chondrites have abundant Type I (MgO-rich) chondrules which are largely dominated by forsteritic olivine. About $10 \%$ of chondrules in $\mathrm{C}$ chondrites, and about $60 \%$ of chondrules in $\mathrm{O}$ chondrites, are Type II chondrules in which olivine is more

214 FeO-rich (e.g. Jones, 2012). Since the sizes of the large sized olivine grains in cosmic 215 spherules are similar to those found in chondrules, this could indicate a chondrule contribution. Matrix is much finer grained than that of chondrules, with grain sizes less than a

217 few $\mu \mathrm{m}$ (Weisberg et al., 2006; Palme et al., 2015). These particular properties of chondrites can be used to interpret observations and trends in cosmic spherules.

The major element composition $\mathrm{Fe}, \mathrm{Si}, \mathrm{Mg}$ of olivine within cosmic spherules can be used to understand the relationships to chondrite components. Minor elements, particularly if they are volatile, can get disturbed during atmospheric entry and inferring the minor element 
chemistry from such elements is not consistent invariably. Fig. 4 shows plots of $\mathrm{FeO} / \mathrm{MgO}$ vs $\mathrm{SiO}_{2} / \mathrm{MgO}$ for various materials in $\mathrm{C}$ chondrites. Chondrules in carbonaceous chondrites of $\mathrm{CO}, \mathrm{CR}$ and $\mathrm{CV}$ groups are dominated by type I, and olivine from these chondrules has a slight spread in oxide $\mathrm{FeO} / \mathrm{MgO}$ ratios that are close to zero (Fig. 4), while those from type II chondrules has $\mathrm{FeO} / \mathrm{MgO}$ ratios around one. The bulk compositions of chondrules from $\mathrm{CM}$ chondrites (El-Quss Abu Said, CM; Hezel and Palme, 2010) have low oxide FeO/MgO ratios, while there is spread in oxide $\mathrm{SiO}_{2} / \mathrm{MgO}$ ratio corresponding to varying olivine / pyroxene abundances. A similar range would be shown for bulk chondrules from all chondrite groups. The bulk matrix compositions for $\mathrm{C}$ chondrites has higher $\mathrm{FeO} / \mathrm{MgO}$ ratios than chondrule olivine (Fig. 4). In particular, the matrix of $\mathrm{CM}$ chondrites has high $\mathrm{FeO} / \mathrm{MgO}$ values when compared with other carbonaceous chondrite groups, as Fe metal has been oxidized. The strong demarcation of the chondrule olivine and matrix silicate data based on $\mathrm{SiO}_{2} / \mathrm{MgO}$ and $\mathrm{FeO} / \mathrm{MgO}$ is diagnostic to estimate the possible contribution of these two major components of chondrites (chondrule and matrix), in cosmic spherules.

Large olivine grains are more likely to be preserved during atmospheric entry compared to smaller grain sizes. The large olivine grains $(>20 \mu \mathrm{m})$ have a different chemistry compared to the smaller olivine grains $(\sim$ few $\mu \mathrm{m})$ within the same cosmic spherules (Fig. 4$)$. The large olivines from the scoriaceous spherules have very low oxide $\mathrm{FeO} / \mathrm{MgO}$ values, similar to compositions of type I chondrule olivine in carbonaceous chondrites. On the other

241 hand, the small olivines from the scoriaceous spherules have high oxide $\mathrm{FeO} / \mathrm{MgO}$ similar to those seen in the matrix of carbonaceous chondrites. In the relict-bearing spherules some large sized olivine grains are slightly more enriched in oxide $\mathrm{FeO} / \mathrm{MgO}$ compared to scoriaceous (Fig. 4a \& b). Compositions of the large relict grains are similar to chondrules from carbonaceous chondrites. In relict-bearing spherules, the small sized olivine grains spread in $\mathrm{FeO} / \mathrm{MgO}$ from chondrule to $\mathrm{CV}$ matrix compositions (Fig. 4b), although the 
majority of the smaller grains are similar to chondrules. We suggest that the scoriaceous and relict-bearing spherules, that contribute to nearly $\sim 10-15 \%$ of total micrometeorite flux received, most likely represent a combination of chondrule and matrix components from carbonaceous chondrites. For porphyritic spherules ( $20 \%$ of total flux received) most large and small olivines have $\mathrm{FeO} / \mathrm{MgO}$ ratios similar to those of chondrules (Fig. 4c). This is the same for the barred spherules (Fig. 4d). The $\mathrm{FeO} / \mathrm{MgO}$ compositions indicate that compositions of large olivine grains in relict-bearing, porphyritic and barred cosmic spherules are consistent with an origin from different types of carbonaceous chondrite chondrules. However, the unequilibrated ordinary chondrites (UOCs) seems to have a similar range of olivine chondrule compositions, although type II chondrules are less FeO-rich and the range of chondrule olivine compositions is narrower compared to carbonaceous chondrites (Fig. 5). In contrast, the spread in matrix of UOCs is larger than that in carbonaceous chondrites (Fig.

4 and 5). The cosmic spherules have large sized olivine grains with compositions consistent with chondrules from different types of chondrites, their compositional range seems to be better matched by $\mathrm{C}$ chondrite chondrules than compared to UOCs. Also, the small size grains do not show the large spread seen in UOC matrix and match better with $\mathrm{C}$ chondrite matrix. Further work on oxygen isotope compositions was performed to make strong association with possible parent bodies.

\subsection{OXYGEN ISOTOPE COMPOSITIONS OF OLIVINES IN COSMIC SPHERULES}

The oxygen isotopic compositional variation in the S-type spherules is a function of the composition of the parent bodies from which they are derived, their evolution in the parent bodies, and any alteration during atmospheric entry due to atmospheric oxygen exchange and ablation. The bulk oxygen isotope compositions of carbonaceous chondrites 
272 fall on or close to the CCAM line, while those of ordinary chondrites lie above the TF line

273 (Clayton et al., 1991; Clayton and Mayeda, 1999). This is also true for the major components

274 of chondrites: chondrules have $\Delta^{17} \mathrm{O}<0 \%$ for carbonaceous and $\geq 0 \%$ for ordinary

275 chondrites (e.g. Clayton et al., 1991; Bridges et al., 1998; Clayton and Mayeda, 1999; Jones

276 et al., 2004; Kita et al., 2010; Rudraswami et al., 2011b; Ushikubo et al., 2012, 2013; Tenner

277 et al., 2013, 2015). The oxygen isotope analyses done on micrometeorites/cosmic spherules

278 by various researchers suggest that they have provenance of carbonaceous chondrites, even

279 though many show disturbance during atmospheric entry (Engrand et al., 1999, 2005;

280 Gounelle et al., 2005; Yada et al., 2005; Suavet et al., 2010; Cordier and Folco, 2014;

281 Rudraswami et al., 2015b). However, the $\delta^{17,18} \mathrm{O}$ values in the individual olivine grains of

282 small sized $(<$ few hundred $\mu \mathrm{m})$ micrometeorites/cosmic spherules appear to be principally

283 dominated by carbonaceous chondrite precursors with only a very small fraction possibly

284 relating to ordinary chondrites, unlike that as suggested by Suavet et al. (2010). We

285 measured a few oxygen isotope compositions that lie above the TF line (e.g. Fig. 2 b) that

286 could have be derived from $\mathrm{O}$ chondrites. An increase in $\delta^{18} \mathrm{O}$ values due to heating

287 experienced by the cosmic spherules during atmospheric entry seems highly plausible

288 (Engrand et al., 2005; Yada et al., 2005; Suavet et al., 2010; Rudraswami et al., 2015b). This

289 is evident from the difference in $\delta^{18} \mathrm{O}$ in small size grains when compared with those having

290 large sizes within the same cosmic spherules (Engrand et al., 2005). Given the same chemical

291 composition and size the grains that are situated close to edge of a spherule are more prone to

292 exchange of atmospheric oxygen. The upper atmosphere at an altitude of $\sim 60 \mathrm{~km}$ has $\delta^{18} \mathrm{O} \sim$

$29323.5 \%$ (Thiemens et al., 1995). Atmospheric oxygen plays a crucial role in changing the

294 oxygen isotopic composition of the olivine grains in the cosmic spherules and will have an

295 impact on interpreting the original isotopic compositions of the spherules. The amount of 
change taking place during its short interaction of $\sim 10-15$ seconds with the atmosphere is very difficult to estimate (Yu et al., 1995; Yada et al., 2005). However some spherules have olivine grains close to the atmospheric values (Fig. 2). Oxygen diffusion in olivine is very slow, and solid-state oxygen-isotope exchange in olivine is not possible during atmospheric entry. However, if an olivine grain was re-crystallized from melt, then it will record the isotopic composition of the melt that has undergone rapid exchange with the surrounding atmosphere (Fagan et al., 2004; Yada et al., 2005). In addition, many grains have higher $\delta^{18} \mathrm{O}$ values, which extend in the same trend beyond the atmospheric value, can be related to evaporation of mass from the particle (e.g. Fig 2c). Two grains located at the edge of porphyritic spherule AAS62-32-P15 (Fig. 3i), with similar forsterite compositions ( Fo77) and similar sizes, have oxygen isotope compositions of $\delta^{18} \mathrm{O} \sim 23 \%$, similar to those of the upper atmosphere. The oxygen isotope exchange depends on the oxygen density, and requires a prolonged heating event to equilibrate with atmospheric oxygen. The size of the grain and mineralogical composition is vital for modifying the oxygen isotope composition. Larger forsterite grains have less atmospheric oxygen exchange compared to small grains of similar composition as is evident from some of the spherules, e.g. AAS38-204-P62; AAS38-204P60; AAS62-61-P107; AAS38-167-P79 (Appendix A, B and Fig. 3). The oxygen isotopic composition of the AAS38-204-P62 (Fig. 1c) with a large grain seems to have preserved the original isotopic composition largely, plus smaller grains that shifted to TF line (Fig. 3e). This is true for AAS62-61-P107 (Fig. 3g) where the relict grain is on CCAM line and the other three smaller and similar sized grains are on the TFL near the stratospheric atmospheric 317 value, and a similar trend is seen in AAS38-204-P60 (Fig. 3f). Oxygen isotope analysis of 318 grains with similar fosteritic composition but with different grain size in AAS38-167-P79 319 (Fig. 3h) shows only a small difference in $\Delta^{17} \mathrm{O}$ values of $\sim 1 \%$ o but a large difference in $\delta^{18} \mathrm{O}$ values. 
$\delta^{18} \mathrm{O}$ compared to the interior chondrite region which is related to atmospheric oxygen

323 exchange during entry, is also true for ordinary chondrites (Clayton et al., 1986; Hezel et al., 2015). However, oxygen isotope exchange in fusion crusts during atmospheric entry has changed $\delta^{18} \mathrm{O}$ by only a few per mil and $\Delta^{17} \mathrm{O}$ values to $\leq 1 \%$. Furthermore, laboratory heating experiments conducted on Murchison (CM) chondrite up to $1000{ }^{\circ} \mathrm{C}$ in a closed system suggest an increase in $\delta^{18} \mathrm{O}$ up to a few per mil, but this has no major bearing on the $\Delta^{17} \mathrm{O}$ values (Clayton et al., 1997). The compiled oxygen isotope data of barred cosmic spherules (Engrand et al., 2005; Yada et al., 2005; Suavet et al., 2010: Fig. 8), that has experienced $\sim 1700^{\circ} \mathrm{C}$, show a marginal increase in $\Delta^{17} \mathrm{O}$ values along with a large increase in $\delta^{18} \mathrm{O}$ values, suggesting that the atmospheric oxygen exchange in the melted cosmic spherules has very limited influence on the $\Delta^{17} \mathrm{O}$ values. The data of barred spherules can be divided into two groups: a) Group I have $\Delta^{17} \mathrm{O}$ values close to or above the TFL (ellipse and circle in Fig. 6) and b) Group II lie below the TFL (rectangle in Fig. 6). Group II has an increasing trend of $\Delta^{17} \mathrm{O}$ with respect to $\delta^{18} \mathrm{O}$ values. The slope of the line suggests $\sim 1 \%$ o change in $\Delta^{17} \mathrm{O}$ for change in $\delta^{18} \mathrm{O}$ of $\sim 10 \%$. The ellipse and circle (group I) marked in Fig. 6 are probably due to the different initial $\delta^{18} \mathrm{O}$ and $\Delta^{17} \mathrm{O}$ of the precursor that has much higher values than those found from the main stream of the particles (rectangle). The large value of $\delta^{18} \mathrm{O}$ in some particles (circle) is probably due to large scale vaporization in addition to atmospheric exchange (Engrand et al., 2005).

In our spherules, mass dependent fractionation in one of the porphyritic spherules, AAS62-32-P18, probably occurred during atmospheric entry. The shift in $\delta^{18} \mathrm{O}$ to $\sim 37-40 \%$ o of olivine grains in this spherule (last two data points on the extreme right hand side of Fig. 7) has resulted in $\Delta^{17} \mathrm{O}$ values slightly above the TF line (Table 1 and Appendix A) from the 
initial composition of $\Delta^{17} \mathrm{O}$ values $\sim-4$ to $-2 \%$. Hence, some of the spherules with high

$346 \delta^{18} \mathrm{O}$ values and low $\Delta^{17} \mathrm{O}$ values (as seen on right hand side of Fig. 7) may be attributed to

347 varied precursor materials from carbonaceous chondrites.

\subsection{IDENTIFYING PRECURSORS OF THE COSMIC SPHERULES}

Most of the olivine analyses from different types of cosmic spherules have $\Delta^{17} \mathrm{O}$ values between -4 to $-2 \%$, with $\leq 5 \%$ having positive values (Fig. 8 ), indicating affinity to carbonaceous chondrites for a majority of grains. The distribution in this histogram is consistent with a compilation of literature data shown in Fig. 9 of Rudraswami et al. (2015b). Positive $\Delta^{17} \mathrm{O}$ values in $\sim 30 \%$ of the particles measured by Suavet et al. (2010) are suggested to be from ordinary chondritic precursors, which is also consistent with the larger diameters of the spherules measured in that study. However, this does not seem to be the case for spherules that are predominately in the size range of $\sim 150-250 \mu \mathrm{m}$. These sizes mostly show $\Delta^{17} \mathrm{O}$ similar to those found in carbonaceous chondrites (Engrand et al., 1999, 2005; Yada et al., 2005; Rudraswami et al., 2015b). Irrespective of the texture the $\Delta^{17} \mathrm{O}$ values seems to have retained by the cosmic spherules. The change in $\delta^{18} \mathrm{O}$ has not led to modify the $\Delta^{17} \mathrm{O}$ values significantly, indicating that temperature range experienced by different types of cosmic spherule during atmospheric entry do retain the $\Delta^{17} \mathrm{O}$ values in olivine grains that can

364 be used to relate to precursors. The study indicates that in the dominant size range $(\sim 100-250$ $\mu \mathrm{m})$ of the cosmic spherules flux the major contribution of $>90 \%$ comes from carbonaceous chondrites. As the size increase, the contribution of the ordinary chondrites towards the flux increases as seen in Suavet et al. (2010). The scoriaceous and relict bearing spherules that

368 have experienced partial melting have oxygen isotopic values consistent with that seen in 
carbonaceous chondrites, except a few that seemed to have undergone large atmospheric exchange (Figs. 3, 7). The porphyritic that have experienced more heating than scoriaceous

371 and relict bearing spherules have large spread in $\delta^{18} \mathrm{O}$ values, but $\Delta^{17} \mathrm{O}<0$ and within the 372 range as observed in carbonaceous chondrites, so is also true for barred spherules (Figs. 7, 8).

373 One of the spherules, AAS38-169-P59, has a large olivine relict grain that has a $\Delta^{17} \mathrm{O}$ value 374 of $5.7 \%$ with relatively low $\delta^{17} \mathrm{O}\left(7.6 \%\right.$ ) and $\delta^{18} \mathrm{O}(3.5 \%$ ) values (Figs. 3a). This grain may 375 have originated from a different type of chondrite that contains ${ }^{16} \mathrm{O}$-poor material. The grain seems to be a part of a porphyritic olivine chondrule. A very high $\Delta^{17} \mathrm{O}(\sim 13 \%)$ value 377 observed by Yada et al. (2005) in cryptocrystalline spherule M03KS063 $\left(\delta^{18} \mathrm{O}=51.8 \%\right.$, $\delta^{17} \mathrm{O}$ $378=40 \%$ ) was interpreted to be derived from a ${ }^{16} \mathrm{O}$-poor body. The possibility of R-chondrite material being the precursor for the olivine grain in AAS38-169-P59 is ruled out as R chondrites have $\Delta^{17} \mathrm{O}$ values only as high as $\sim 3 \%$ o (Kallemeyn et al., 1996; Fig. 7). Our interpretation is that the high $\Delta{ }^{17} \mathrm{O}$ observed in the spherule AAS38-169-P59 is the result of

${ }^{16} \mathrm{O}$-poor and high $\Delta^{17} \mathrm{O}$ precursor properties. The possibility of oxygen isotope exchange for spherule AAS38-169-P59 during atmospheric entry that has pushed $\Delta^{17} \mathrm{O}$ values to such a high value is unlikely as oxygen is a minor constituent at high altitude (Thiemens et al., 1995; Yada et al., 2005). If the above is true then the oxygen isotopic composition in the solar nebula may be considerably more heterogeneous than is currently assumed, based on meteorite studies alone.

The bulk oxygen isotope ratios of cosmic spherules that contain olivine grains of different sizes with different forsterite contents, along with other minerals, can leads to 390 changes in $\Delta^{17} \mathrm{O}$ values during atmospheric entry. The majority of the data have $\Delta^{17} \mathrm{O}$ below 391 the TF line, with a few exceptions that can be attributed to alteration during entry or possibly 392 derivation from ordinary chondrites (Fig. 7). There are some spherules (e.g. AAS38-188-P72, 
393 AAS38-204-P68, AAS62-32-P18, and AAS38-204-P16) that have $\Delta^{17} \mathrm{O}$ lying between 0 to 2

$394 \%$ similar to those seen in ordinary chondrites. Even the large value of $\delta^{18} \mathrm{O}$ has not been able

395 to alter the $\Delta^{17} \mathrm{O}$ values significantly above the TF line (Fig. 7). In addition, the FeO/MgO

396 versus $\mathrm{SiO}_{2} / \mathrm{MgO}$ of large olivine grains in cosmic spherules with different textures are

397 similar to chondrules (Fig. 4). Matrix in CI and CM chondrites has $\Delta^{17} \mathrm{O}$ values close to TFL

398 (Rowe et al., 1994) suggesting some spherules may possibly have CI and CM chondritic

399 precursors. The scoriaceous spherules can be associated with matrix type material

400 predominantly found in CI or CM chondrites. However, relict grain bearing spherules can be

401 partially associated with $\mathrm{CI} / \mathrm{CM}$ and with other carbonaceous chondrites which have higher

402 abundances of chondrules such as CO, CV, CK, CR (Fig. 4). The chondrule dominance is

403 also visible in porphyritic spherules and barred spherules. Since chondrules are a major

404 component in carbonaceous chondrites (except CI and CM), with $\Delta^{17} \mathrm{O}$ values similar to those

405 seen in cosmic spherules, we suggest that carbonaceous chondrites chondrules could be a

406 major component of the micrometeorite flux. The high porosity of the carbonaceous

407 chondrites $(\sim 40-60 \%)$ compared to ordinary chondrites $(\sim 20-30 \%)$ has the advantage of

408 liberating a large amount of dust in a smaller size range during catastrophic collisions (Britt

409 et al., 2002; Consolmagno et al., 2008), which would be consistent with the micrometeorite

410 flux being dominated by carbonaceous chondrite material. In contrast, collision involving

411 ordinary chondrites may release relatively larger sized particles, and the oxygen isotope

412 composition of large cosmic spherules analyzed seem consistent with them (Suavet et al.,

413 2010).

414

415

6. CONCLUSIONS

416 
417 Understanding the chemical and isotopic composition of extraterrestrial particles is 418 central for understanding Solar System evolution. However, for cosmic spherules there are

419 limitations on our understanding as cosmic spherules change their original compositions as 420 they enter the Earth's atmosphere. In our study, oxygen isotope compositions in a majority 421 of olivine grains from different textural types of cosmic spherules range from -4 to $-2 \%$ in $422 \Delta \Delta^{17} \mathrm{O}$ values. The oxygen isotopic composition of olivines in cosmic spherules indicates that 423 chondrules and isolated grains from carbonaceous chondrites have largely contributed to the 424 flux of the micrometeorites. AAS38-169-P59 has a $\Delta^{17} \mathrm{O} \sim 5.7 \%$, suggesting it to originate 425 from some unidentified source. In addition, a small fraction of cosmic spherules display 426 oxygen isotope evidence that can be possibly related to ordinary chondrites.

427 
430 Research XII Plan) and PLANEX (Physical Research Laboratory, Ahmedabad) project, under

431 which this work has been carried out. We also thank Vijay Khedekar for his assistance and 432 support during the electron microprobe work. NGR thanks Indo-US Science and Technology 433 Forum (IUSSTF) for providing the fellowship and support to carry out this research work. 434 This is NIO contribution No. $\mathrm{xxxx}$.

435 
437 Beckerling W. and Bischoff A. (1995) Occurrence and composition of relict minerals in micrometeorites from Greenland and Antarctica-implications for their origins. Planet. Space Sci. 43, 435-449.

Brearley A. J. and Jones R. H. (1998) Chondritic meteorites. In Planetary Materials (ed. J. J. Papike). Reviews in Mineralogy 36, pp. 3-1 to 3-398.

442

Bridges J. C., Franchi I. A., Hutchison R., Sexton A. S. and Pillinger C. T. (1998) Correlated mineralogy, chemical compositions, oxygen isotopic compositions and size of chondrules. Earth Planet. Sci. Lett. 155, 183-196.

Britt D. T., Yeomans D., Housen K., and Consolmagno G. (2002) Asteroid density, porosity, and structure. In Asteroids III (W. F. Bottke Jr. et al., eds.). Univ. of Arizona, Tucson, pp. $485-500$.

Brownlee D. E., Bates B. and Schramm L. (1997) The elemental composition of stony cosmic spherules. Meteorit. Planet. Sci. 32, 157-175.

Clayton R. N. (1993) Oxygen isotopes in meteorites. Annu. Rev. Earth Planet. Sci. 21, $115-149$.

Clayton R. N. and Mayeda T.K. (1999) Oxygen isotope studies of carbonaceous chondrites. Geochim. Cosmochim. Acta 63, 2089-2104.

Clayton R. N., Mayeda T. M., and Brownlee D. E. (1986) Oxygen isotopes in deep-sea spherules. Earth Planet. Sci. Lett. 79, 235-240.

Clayton R. N., Mayeda T. K., Goswami J. N., and Olsen E. J. (1991) Oxygen isotope studies of ordinary chondrites. Geochim. Cosmochim. Acta 55, 2317-2337. 
Clayton R. N., Mayeda T. M., Hiroi T., Zolensky M. and Lipschutz M. E. (1997) Oxygen isotopes in laboratory heated CI and CM chondrites. Meteorit. Planet. Sci., 32, p. A30.

Consolmagno G. J., Britt D.T., Macke R. J. (2008) The significance of meteorite density and porosity. Chemie der Erde, 68, 1-29.

Cordier C., Folco L., Suavet C., Sonzogni C. and Rochette P. (2011) Major, trace element and oxygen isotope study of glass cosmic spherules of chondritic composition: The record of their source material and atmospheric entry heating. Geochim. Cosmochim. Acta 75, 5203-5218.

467

Engrand C., McKeegan K.

K. D. and Leshin L.

. A. (1999) Oxygen isotopic compositions of individual minerals in Antarctic micrometeorites: Further links to carbonaceous chondrites. Geochim. Cosmochim. Acta 63, 2623-2636.

Engrand C., McKeegan K. D., Leshin L.A., Herzog G.F., Schnabel C., Nyquist L.E. and Brownlee D. E. (2005) Isotopic compositions of oxygen, iron, chromium, and nickel

Fagan T. J., Krot A. N., Keil K. and Yurimoto H. (2004) Oxygen isotopic evolution of 475

Genge M. J., Engrand C., Gounelle M. and Taylor S. (2008) The classification of amoeboid olivine aggregates in the reduced CV3 chondrites Efremovka, Vigarano, and Leoville. Geochim. Cosmochim. Acta 68, 2591-2611.

Gounelle M., Engrand C., Maurette M., Kurat G., McKeegan K. D. and Brandsta“tter F. (2005) Small Antarctic micrometeorites: a mineralogical and in situ oxygen isotopic study. Meteorit. Planet. Sci. 40, 917-932. 
Greshake A., Klock W., Arndt P., Maetz M., Flynn G. J., Bajt S. and Bischoff A. (1998) Heating experiments simulating atmospheric entry heating of micrometeorites: Clues to their parent body sources. Meteorit. Planet. Sci. 33, 267-290.

Hezel D.C. and Palme H. (2010) The chemical relationship between chondrules and matrix and the chondrule matrix complementarity. Earth Planet. Sci. Lett. 294, 85-93.

Hezel D. C., Poole G. M., Hoyes J., Coles B. J., Unsworth C., Albrecht N., Smith C., Rehkämper M., Pack A., Genge M., and Russell S. S. (2015) Fe and O isotope composition of meteorite fusion crusts: Possible natural analogues to chondrule formation? Meteorit. Planet. Sci. 50, 229-242.

Hutchison R., Alexander C. M. O’D. and Barber D. J. (1987) The Semarkona meteorite: First recorded occurrence of smectite in an ordinary chondrite and its implications. Geochim. Cosmochim. Acta 51, 1875-1882.

Jones R. H. (2012) Petrographic constraints on the diversity of chondrule reservoirs in the protoplanetary disk. Meteorit. Planet. Sci. 47, 1176-1190.

Jones R. H., Leshin L. A., Guan Y., Sharp Z. D., Durakiewicz T. and Schilk A. J. (2004) Oxygen isotope heterogeneity in chondrules from the Mokoia CV3 carbonaceous chondrite. Geochim. Cosmochim. Acta 68, 3423-3438.

Kallemeyn G. W., Rubin A. E. and Wasson J. T. (1996) The compositional classification of chondrites: The R chondrite group. Geochim. Cosmochim. Acta 60, 2243-2256.

Kita N. T., Nagahara H., Tachibana S., Tomomura S., Spicuzza M. J., Fournelle J. H. and Valley J. W. (2010) High precision SIMS oxygen three isotope study of chondrules in LL3 chondrites: Role of ambient gas during chondrule formation. Geochim. Cosmochim. Acta 74, 6610-6635. 
505 Rudraswami N. G. (2009). Isotopic studies on evolution of early solar system objects by an Ion Microprobe. Ph.D. thesis. Gujarat University Ahmedabad.

507 Kurat G., Koeberl C., Presper T., Brandstatter F. and Maurette M. (1994) Petrology and geochemistry of Antarctic micrometeorites. Geochim. Cosmochim. Acta 58, 38793904.

Leshin L. A., Rubin A. E. and McKeegan K. D. (1997) The oxygen isotopic composition of olivine and pyroxene from CI chondrites. Geochim. Cosmochim. Acta 61, 835-845. micrometeoroids entering the Earth's atmosphere. Icarus 89, 26-43.

Love S. G. and Brownlee D. E. (1993) A Direct Measurement of the Terrestrial Mass Accretion Rate of Cosmic Dust. Science 262, 550-553.

Matrajt G., Guan Y., Leshin L., Taylor S., Genge M., Joswiak D. and Brownlee D. (2006) Oxygen isotope measurements of individual unmelted Antarctic micrometeorites. Geochim. Cosmochim. Acta 70, 4007-4018.

Matsunami S., Nishimura H. and Takeshi H. (1990) The chemical compositions and textures of matrices and chondrule rims of unequilibrated chondrites-II. Their constituents and implications for the formation of matrix olivine. Proc. NIPR Symp. Antarct.

Plane J. M. C. (2012) Cosmic dust in the earth's atmosphere. Chem. Soc. Rev. 41, 65076518.

Palme H., Hezel D. C. and Ebel D. S. (2015) The origin of chondrules: Constraints from matrix composition and matrix-chondrule complementarity. Earth Planet. Sci. Lett. 411, 11-19. 
Prasad M. S., Rudraswami N. G. and Panda D. K. (2013) Micrometeorite flux on earth during the last $\sim 50,000$ years. J. Geophy. Res.118, 2381-2399.

Rowe M. W., Clayton R. N. and Mayeda T. K. (1994) Oxygen isotopes in separated components of CI and CM meteorites. Geochim. Cosmochim. Acta 58, 5341-5347.

Rudraswami N. G., Parashar K. and Shyam Prasad M. (2011a) Micrometer and nanometer size platinum group nuggets in micrometeorites from the deep sea sediments of Indian Ocean. Meteorit. Planet. Sci. 46, 470-491.

Rudraswami N. G., Ushikubo T., Nakashima D. and Kita N. T. (2011b) Oxygen isotope systematics of chondrules in Allende CV3 chondrite: high precision ion microprobe studies. Geochim. Cosmochim. Acta 75, 7596-7611.

Rudraswami N.G., Shyam Prasad M., Babu E.V.S.S.K., Vijaya Kumar T., Feng W. and Plane J.M.C. (2012) Fractionation and fragmentation of glass cosmic spherules during atmospheric entry. Geochim. Cosmochim. Acta 99, 110-127.

Rudraswami N. G., Shyam Prasad M., Dey S., Plane J. M. C., Feng W. and Taylor S. (2015a). Evaluating changes in the elemental composition of micrometeorites during entry into the Earth's atmosphere. The Astrophy. J. 814, 78.

Rudraswami N. G., Prasad M. S., Nagashima K., and Jones R. H. (2015b) Oxygen isotopic composition of relict olivine grains in cosmic spherules: Links to chondrules from carbonaceous chondrites. Geochim. Cosmochim. Acta 164, 57-70.

Suavet C., Alexandre A., Franchi I. A., Gattacceca J., Sonzogni C., Greenwood R. C., Folco L. and Rochette P. (2010) Identification of the parent bodies of micrometeorites with high-precision oxygen isotope ratios. Earth and Planet. Sci. Lett. 293, 313-320. 
550 Taylor S., Lever J. H. and Harvey R. P. (1998) Accretion rate of cosmic spherules measured at the South Pole. Nature 392, 899-903.

552

Tenner T. J., Ushikubo T., Kurahashi E., Kita N. T. and Nagahara H. (2013) Oxygen isotope systematics of chondrule phenocrysts from the CO3.0 chondrite Yamato 81020: evidence for two distinct oxygen isotope reservoirs. Geochim. Cosmochim. Acta 102, 226-245.

Tenner T. J., Nakashima D., Ushikubo T., Kita N. T. and Weisberg M. K. (2015) Oxygen isotope ratios of FeO-poor chondrules in CR3 chondrites: influences of dust enrichment and $\mathrm{H} 2 \mathrm{O}$ during chondrule formation. Geochim. Cosmochim. Acta 148, $228-250$.

Thiemens M H., Jackson T., Zipf E C., Erdman P W. and Van Egmond C. (1995) Carbon dioxide and oxygen isotope anomalies in the mesosphere and stratosphere. Science 270, 969-972.

Ushikubo T., Kimura M., Kita N. T. and Valley J. W. (2012) Primordial oxygen isotope reservoirs of the Solar nebula recorded in chondrules in Acfer 094 carbonaceous chondrites. Geochim. Cosmochim. Acta 90, 242-264.

Ushikubo T., Nakashima D., Kimura M., Tenner T. J. and Kita N. T. (2013) Contemporaneous formation of chondrules in distinct oxygen isotope reservoirs. Geochim. Cosmochim. Acta 109, 280-295.

Weisberg M. K., McCoy T. J. and Krot A. N. (2006) Systematics and evaluation of meteorite classification. In: Lauretta, D., McSweenJr., H.Y. (Eds.), Meteorites and the Early Solar System II. University of Arizona, Tucson, pp.19-52. 
572 Weisberg M. K., Zolensky M. E. and Prinz M. (1997) Fayalitic olivine in matrix of the Krymka LL3.1 chondrite: Vapor-solid growth in the solar nebula. Meteorit. Planet. Sci. 32, 791-801.

575 Yada T., Nakamura T., Takaoka N., Noguchi T., Terada K., Yano H., Nakazawa T. and Kojima H. (2004) The global accretion rate of extraterrestrial materials in the last glacial period estimated from the abundance of micrometeorites in Antarctic glacier ice. Earth Planets Space 56, 67-79.

Yada T., Nakamura T., Noguchi T., Matsumoto N., Kusakabe M., Hiyagon H., Ushikubo T., Sugiura N., Kojima H. and Takaoka N. (2005) Oxygen isotopic and chemical compositions of cosmic spherules collected from the Antarctic ice sheet: implications for their precursor materials. Geochim. Cosmochim. Acta 69, 5789-5804.

583 Yu Y., Hewins R. H., Clayton R. N. and Mayeda T. K. (1995) Experimental study of high 584 temperature oxygen isotope exchange during chondrule formation. Geochim. Cosmochim. Acta 59, 2095-2104.

586 Yurimoto H., Krot A. N., Choi B.-G., Aleon J., Kunihiro T. and Brearley A. J. (2008) Oxygen isotopes of chondritic components. In Oxygen in the Solar System, RIMS vol. 68, ed. G. J. MacPherson, 141-186. 


\section{$591 \quad$ Figure 1.}

592 Representative backscattered electron (BSE) images of different types of cosmic spherules: a

593 and b): scoriaceous; $c$ and d): relict grain bearing; e and f): porphyritic; $g$ and $h$ ): barred. The

594 circles indicate the regions of ion microprobe analyses and the numbers are the $\Delta^{17} \mathrm{O}$ values

595 for that particular analysis. The chemical compositions and oxygen isotope data of the region

596 of analyses are provided in Appendix B and Table 1, respectively.

597

\section{Figure 2.}

599 Oxygen isotope compositions of different types of cosmic spherules: a) scoriaceous, b) relict

600 grain bearing, c) porphyritic and d) barred, measured using ion microprobe. The star symbol

601 is for stratospheric oxygen isotope composition. BSE images of the cosmic spherules and the

602 regions of analyses are shown in Appendix A. The solid lines labelled are the terrestrial

603 fractionation (TF) line, having slope of $\sim 0.52$, and the carbonaceous chondrite anhydrous

604 mineral (CCAM) line, with a slope of $\sim 0.94$ (Clayton et al., 1993). All error bars are $2 \sigma$.

605

606

$607 \quad$ Figure 3.

608 Oxygen isotope compositions of relict-bearing and porphyritic cosmic spherules whose BSE

609 images are shown in Appendix A. The solid lines are terrestrial fractionation (TF) and

610 chondrite anhydrous mineral (CCAM) lines, having slope of $\sim 0.52$ and $\sim 0.94$, respectively 
611 (Clayton et al., 1993). All error bars are $2 \sigma$. Appendix B and Tables 1 provide the chemical

612 composition and oxygen isotopic data of spherules.

613

614

$615 \quad$ Figure 4.

616 Oxide $\mathrm{FeO} / \mathrm{MgO}$ vs. $\mathrm{SiO}_{2} / \mathrm{MgO}$ of large $(\geq 20 \mu \mathrm{m})$ and smaller sized ( few $\left.\mu \mathrm{m}\right)$ olivines for

617 different types of cosmic spherules, compared with olivine compositions of chondrules, 618 except for CM chondrules (bulks), and bulk matrix compositions from several carbonaceous 619 chondrites. The data of chondrules (Allende CV: Rudraswami et al., (2011b); MET 00426 620 (CR) and QUE99177 (CR): Tenner et al. (2015); Y-81020 (CO): Tenner et al. (2013); El 621 Quess Abu Said (CM): Palme et al. (2015)) and matrix (Mokoia (CV), Efremovka (CV), 622 Renazzo (CR), Kainsaz (CO), El-Quss Abu Said (CM): Palme et al. (2015)) of different 623 carbonaceous chondrites are included for comparison. The regions defined by chondrules and 624 matrix are identified in Fig.4a.

\section{$625 \quad$ Figure 5.}

626 Oxide $\mathrm{FeO} / \mathrm{MgO}$ vs. $\mathrm{SiO}_{2} / \mathrm{MgO}$ of large $(\geq 20 \mu \mathrm{m})$ and smaller sized $(\sim$ few $\mu \mathrm{m})$ olivines for 627 different types of cosmic spherules, compared with olivine compositions of chondrules and 628 bulk matrix compositions from several unequilibrated ordinary chondrites (UOCs, 629 Rudraswami, 2009). The data for matrix are taken from Matsunami et al. (1990), Hutchison 630 et al. (1987) and Weisberg et al. (1997).

631

632 


\section{Figure 6.}

634 Plot of $\Delta^{17} \mathrm{O}$ vs. $\delta^{18} \mathrm{O}$ of different types of spherules analysed in this study. Most of the data 635 lie below the TF line which indicates that the micrometeorite flux is dominated by 636 carbonaceous chondrites. The ellipse and rectangle areas are for the ordinary and $\mathrm{R}$ 637 chondrites, respectively (Clayton et al., 1991; Clayton and Mayeda, 1999). The atmospheric 638 data is shown by asterisk (Thiemens et al., 1995). Some of the data lying above the TF line 639 may be derived from ordinary chondrites, however, AAS38-169-P59 has $\Delta^{17} \mathrm{O} \sim 5.7 \%$ that 640 may be from a previously un-sampled isotopic reservoir. All error bars are $2 \sigma$.

641

$642 \quad$ Figure 7.

643 Plot of $\Delta^{17} \mathrm{O}$ vs. $\delta^{18} \mathrm{O}$ of barred spherules measured using IR-laser fluorination coupled with 644 mass spectrometry (Suavet et al., 2010) and ion microprobe (Engrand et al., 2005; Yada et 645 al., 2005; this work). Ion microprobe data from previous studies were measured using a de646 focused primary beam, providing data similar to those of bulk chemical composition. The 647 barred spherule data can be divided into two groups: one with $\Delta^{17} \mathrm{O} \geq 0$ (marked ellipse and 648 circle) and the other with $<0$ (marked square). The data with $\Delta^{17} \mathrm{O}<0$ shows an increase in $649 \Delta^{17} \mathrm{O}$ as $\delta^{18} \mathrm{O}$ values goes up.

650

\section{$651 \quad$ Figure 8.}

652 Histogram of $\Delta^{17} \mathrm{O}$ of olivine grains in different types of cosmic spherules analysed in this 653 study. 
Fig. 1
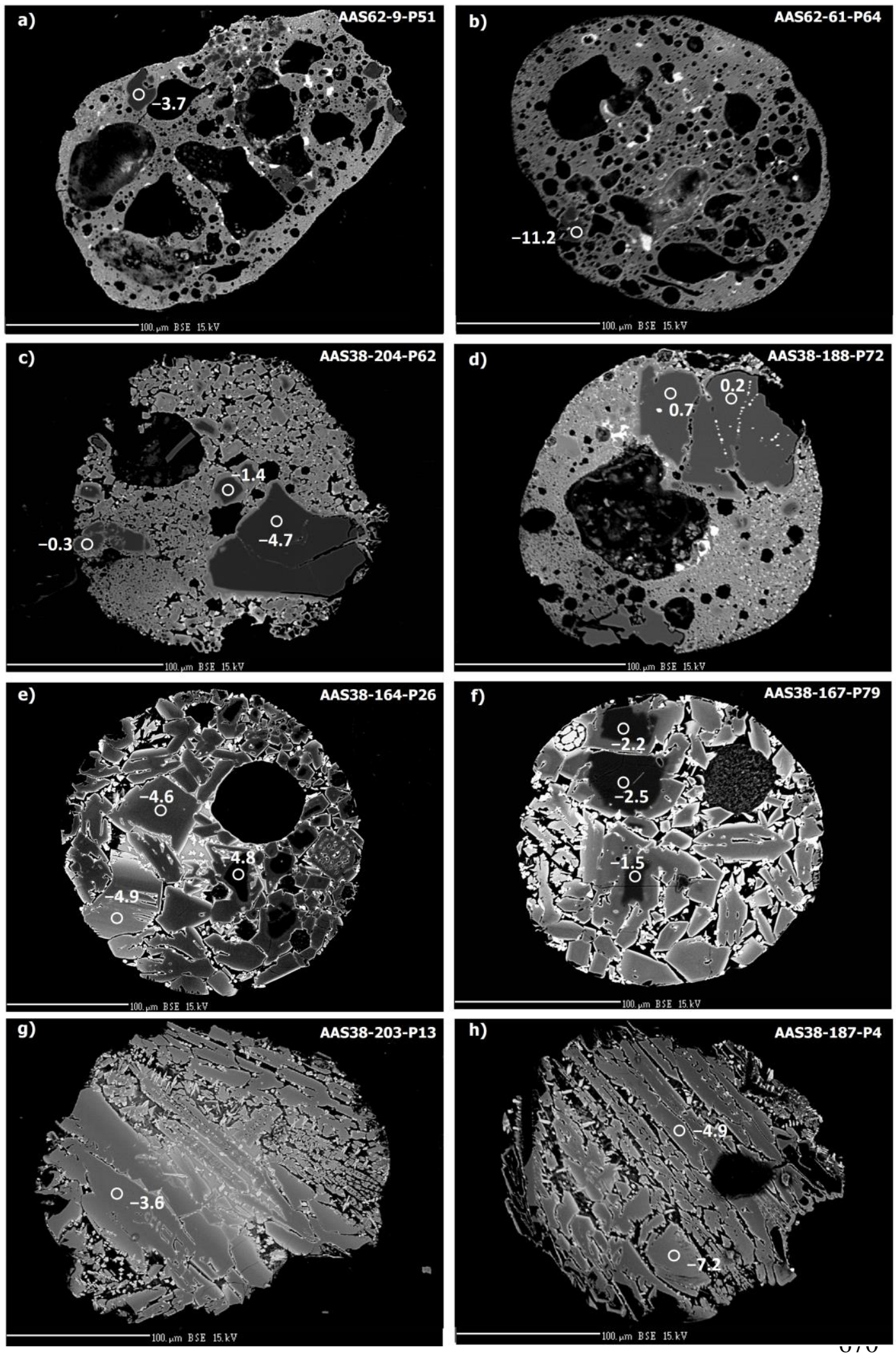
Fig. 2

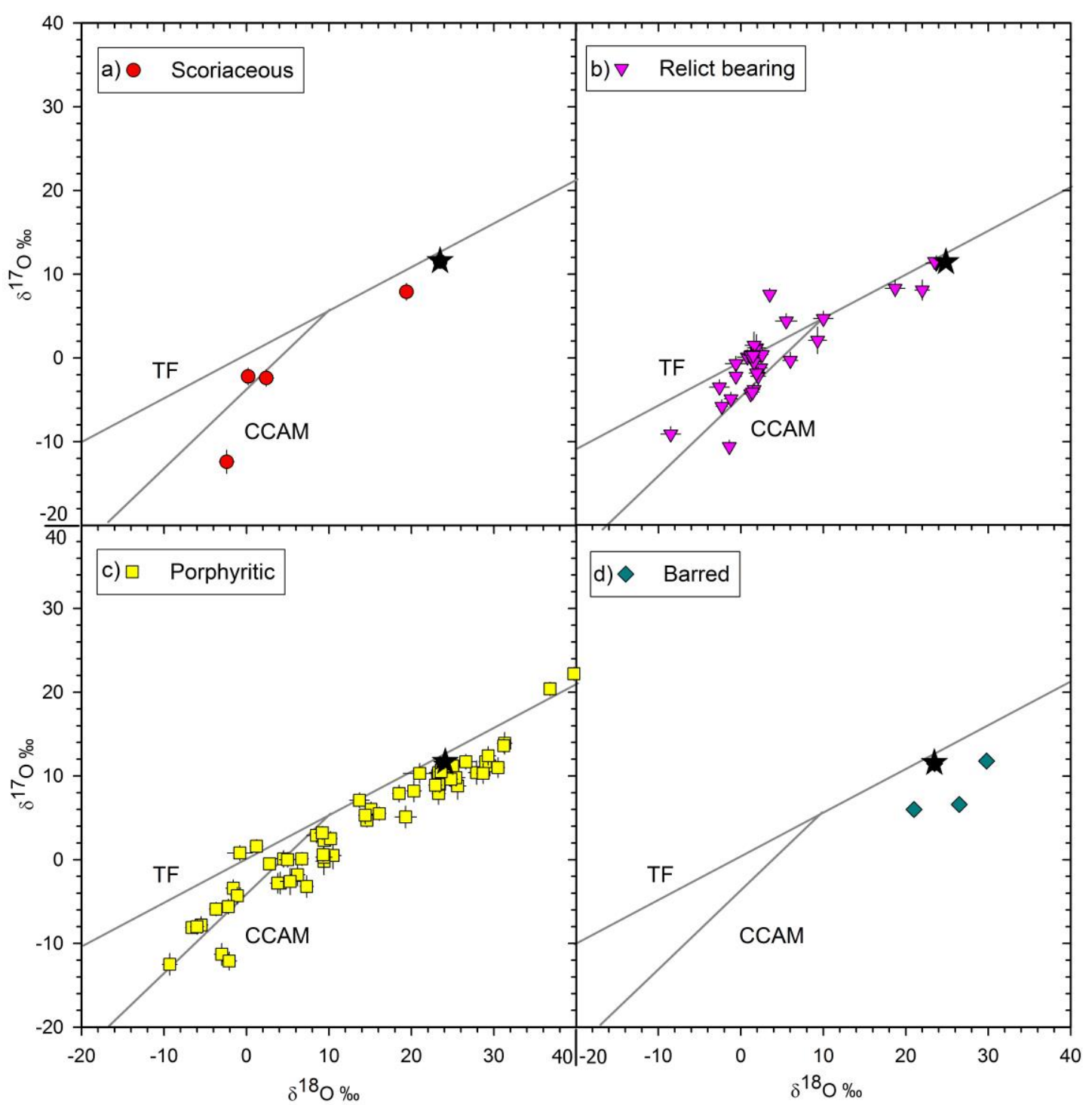

672

673

674

675

676

677 
Fig. 3
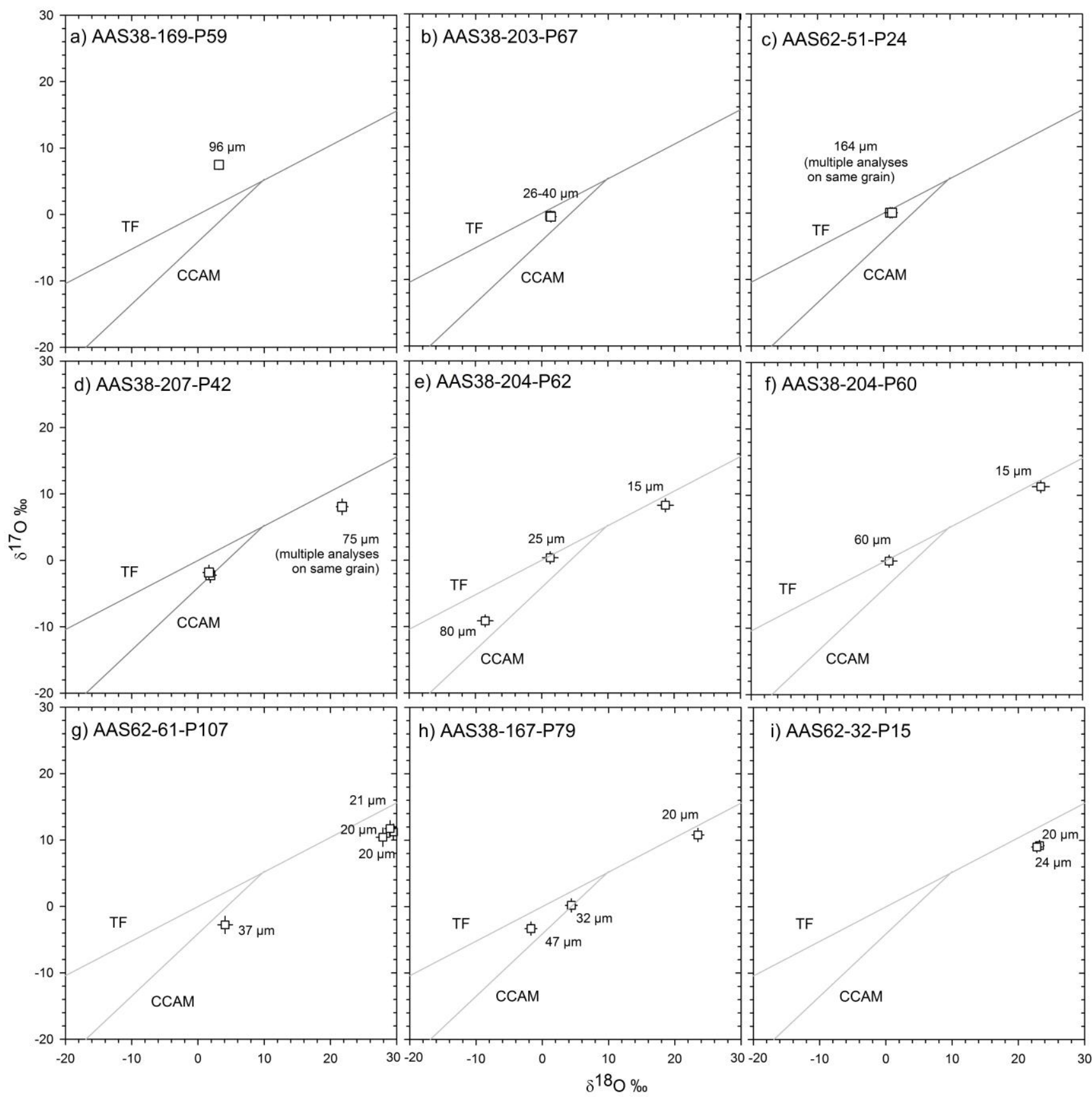

i) AAS62-32-P15

678

679

680

681

682 
Fig. 4
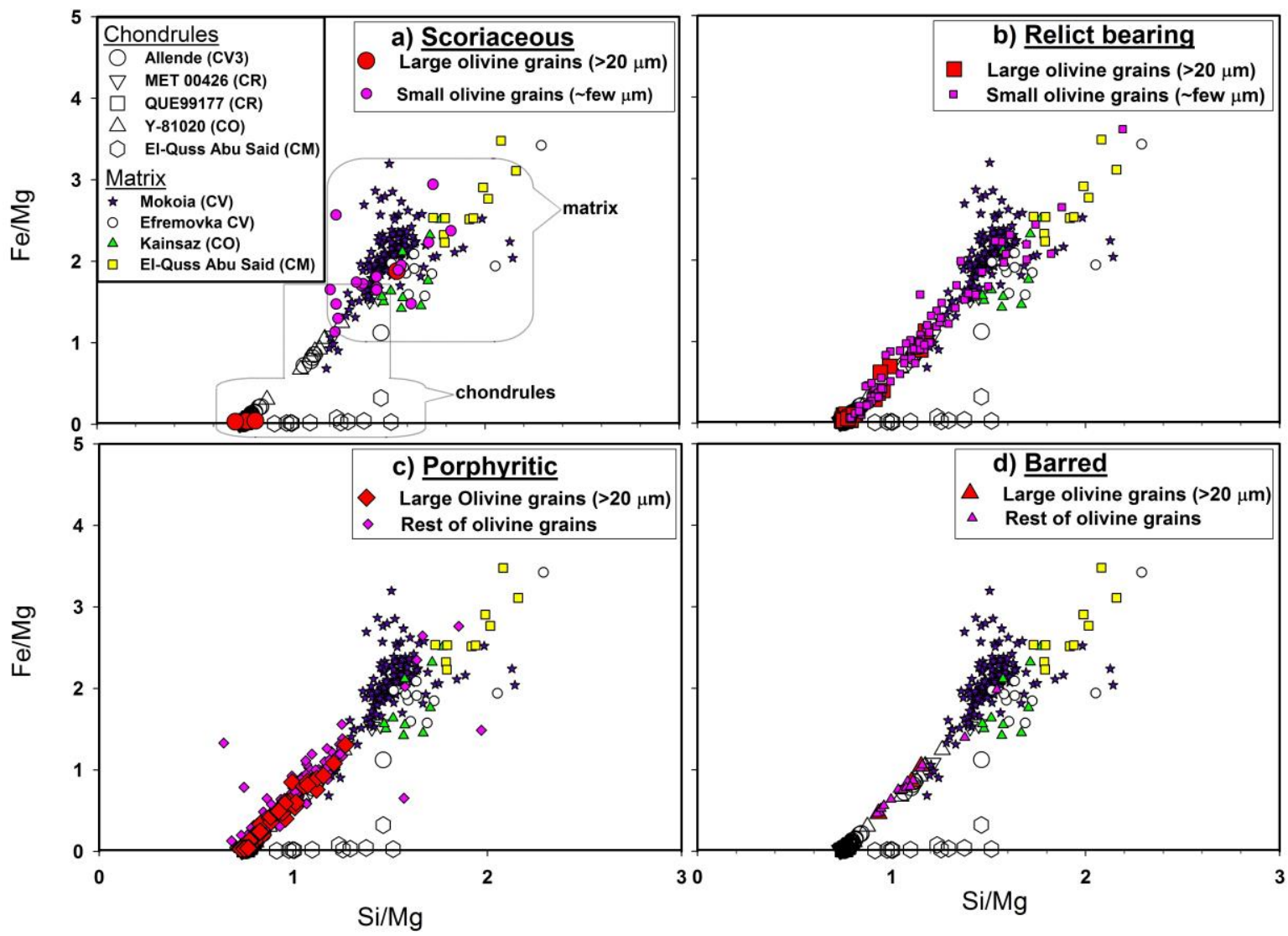

685

686

687

688

689

690

691 
Fig. 5
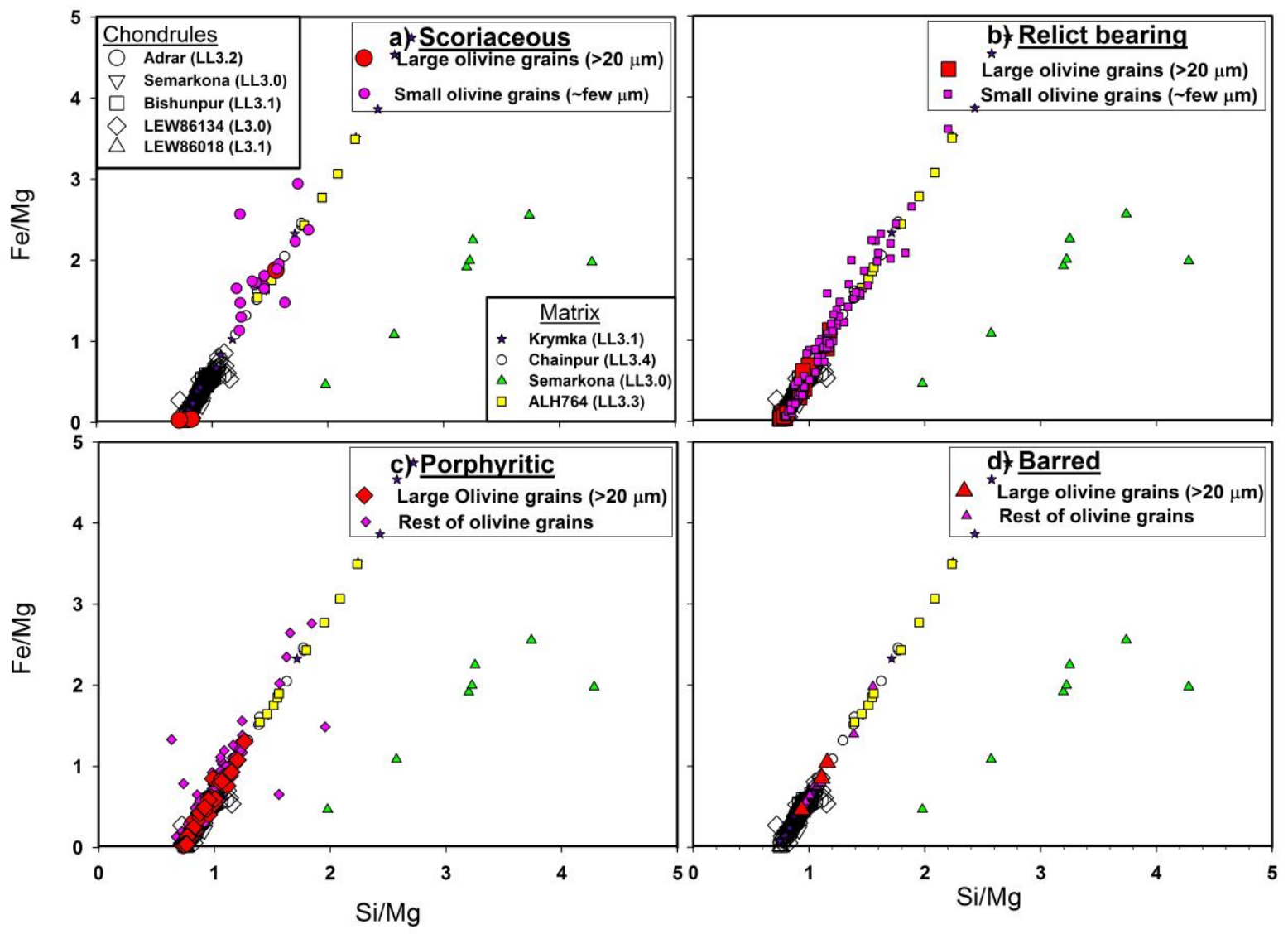

693

694

695

696

697

698

699 
Fig.6

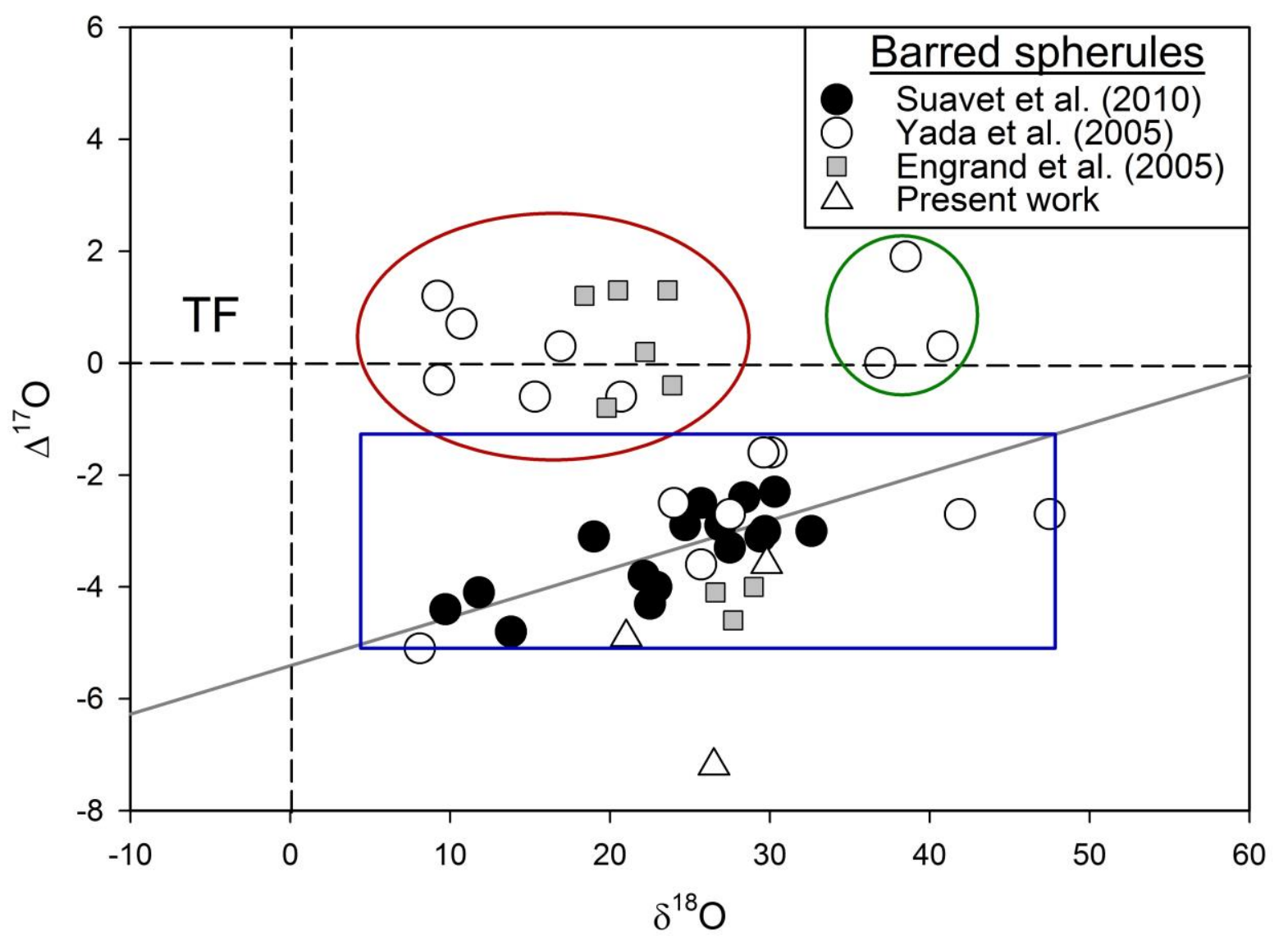

702

703

704

705

706

707

708

709 
Fig. 7

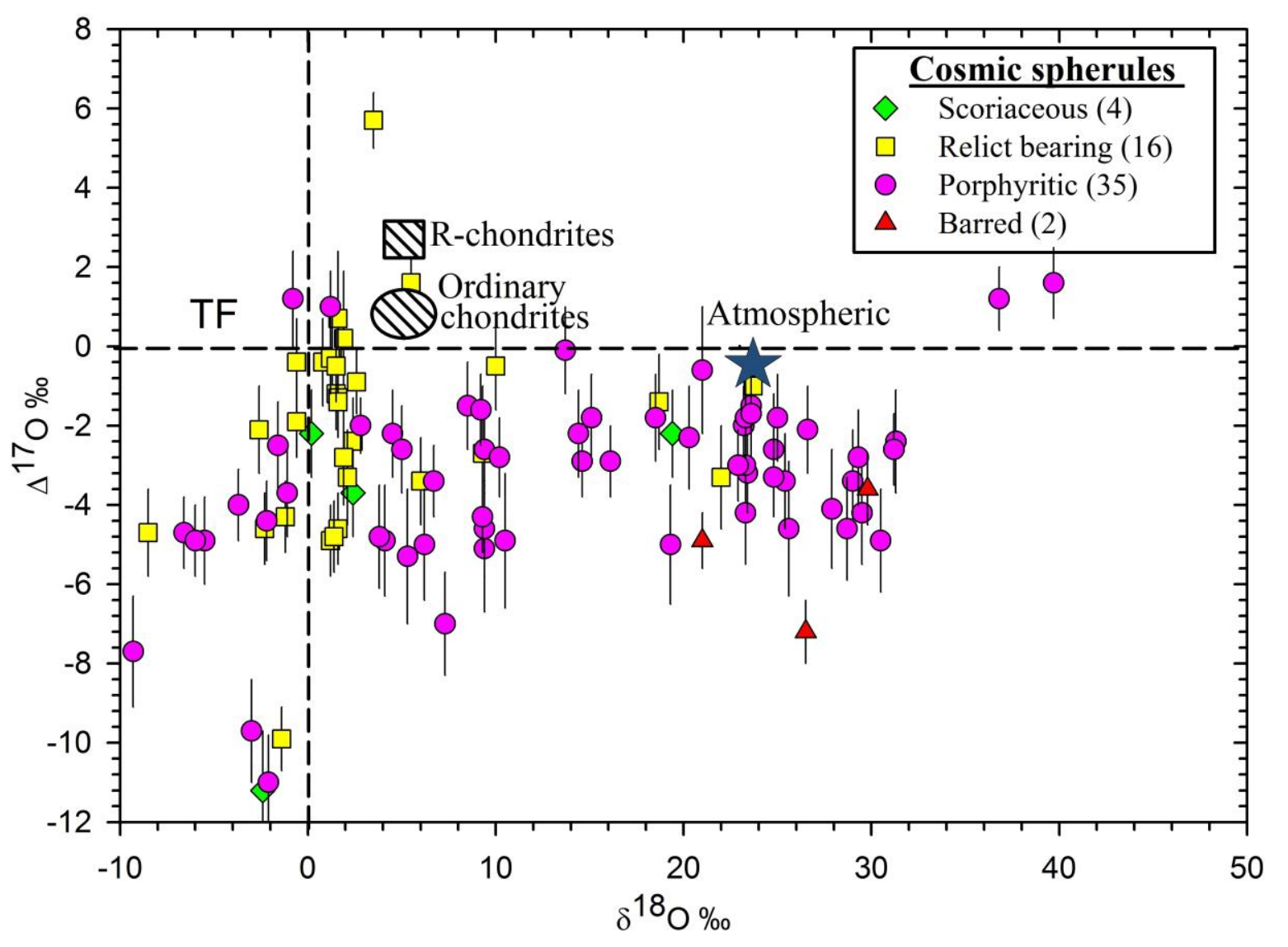

711

712

713

714

715

716

717

718 
Fig. 8

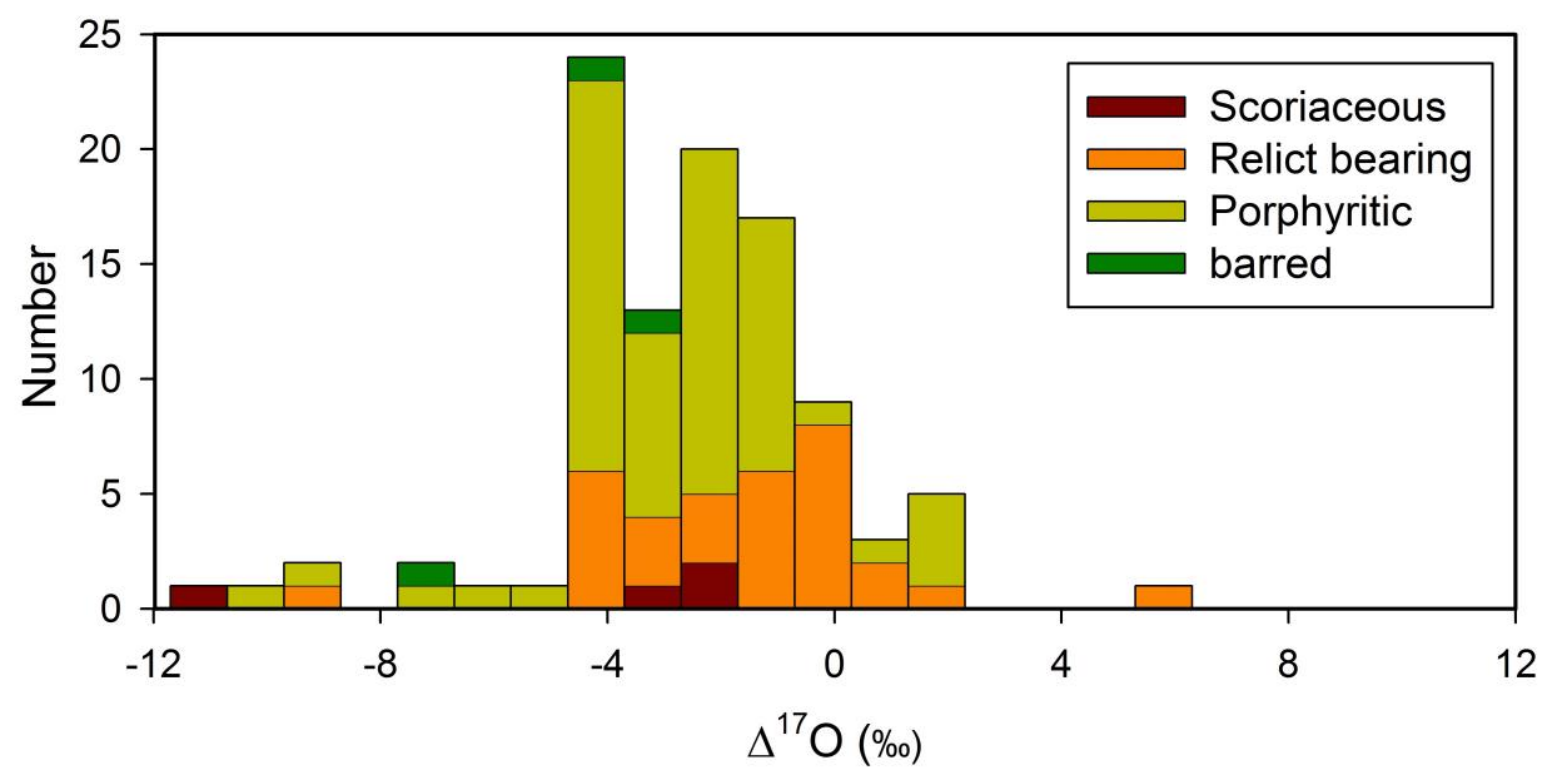

721

722

723

724

725

726

727

728

729 
Table 1. Oxygen isotope compositions of olivine grains in cosmic spherules. The oxygen isotope $\delta$ values are in \%o.

\begin{tabular}{|c|c|c|c|c|c|c|c|c|}
\hline Spherule \# & Spot\# & Fo $(\%)$ & $\delta^{18} \mathrm{O}$ & $2 \sigma$ & $\delta^{17} \mathrm{O}$ & $2 \sigma$ & $\Delta^{17} \mathrm{O}$ & $2 \sigma$ \\
\hline \multicolumn{9}{|l|}{ 1) Scoriaceous } \\
\hline AAS62-61-P64 & 1 & 98.6 & -2.4 & 0.9 & -12.4 & 1.4 & -11.2 & 1.5 \\
\hline AAS62-9-P43 & 1 & 98.3 & 19.4 & 0.8 & 7.9 & 1.0 & -2.2 & 1.1 \\
\hline AAS62-9-P51 & 1 & 99.0 & 2.4 & 0.9 & -2.4 & 1.0 & -3.7 & 1.1 \\
\hline AAS62-9-P54 & 1 & 48.9 & 0.2 & 0.8 & -2.2 & 1.0 & -2.2 & 1.1 \\
\hline \multicolumn{9}{|l|}{ 2) Relict bearing } \\
\hline AAS38-188-P52 & 1 & 98.0 & 9.3 & 1.1 & 2.1 & 1.6 & -2.7 & 1.7 \\
\hline \multirow[t]{2}{*}{ AAS38-188-P72 } & 1 & 98.6 & 1.9 & 1.1 & 1.2 & 1.6 & 0.2 & 1.7 \\
\hline & 2 & 98.4 & 1.6 & 1.1 & 1.5 & 1.6 & 0.7 & 1.7 \\
\hline \multirow{2}{*}{ AAS38-204-P60 } & 1 & 61.5 & 0.8 & 1.2 & 0.1 & 0.9 & -0.4 & 1.1 \\
\hline & 2 & 48.1 & 23.7 & 1.3 & 11.3 & 0.9 & -1.0 & 1.1 \\
\hline \multirow[t]{3}{*}{ AAS38-204-P62 } & 1 & 99.1 & -8.5 & 1.2 & -9.1 & 0.9 & -4.7 & 1.1 \\
\hline & 2 & 98.5 & 18.7 & 1.2 & 8.3 & 1.0 & -1.4 & 1.2 \\
\hline & 3 & 97.9 & 1.3 & 1.2 & 0.4 & 0.9 & -0.3 & 1.1 \\
\hline \multirow[t]{3}{*}{ AAS38-204-P66 } & 1 & 95.4 & -2.6 & 1.2 & -3.5 & 0.9 & -2.1 & 1.1 \\
\hline & 2 & 95.2 & -0.6 & 1.3 & -0.7 & 0.9 & -0.4 & 1.1 \\
\hline & 3 & 94.9 & 10.0 & 1.2 & 4.7 & 0.9 & -0.5 & 1.1 \\
\hline AAS38-204-P68 & 1 & 97.7 & 5.5 & 1.3 & 4.4 & 0.9 & 1.6 & 1.1 \\
\hline \multirow[t]{2}{*}{ AAS38-167-P28 } & 2 & 72.3 & 2.4 & 0.8 & -1.2 & 1.0 & -2.4 & 1.1 \\
\hline & 3 & 98.6 & 6.0 & 0.9 & -0.3 & 1.0 & -3.4 & 1.1 \\
\hline \multirow[t]{2}{*}{ AAS62-32-P16 } & 1 & 98.9 & -2.3 & 0.7 & -5.8 & 0.8 & -4.6 & 0.9 \\
\hline & 2 & 96.5 & -1.2 & 0.8 & -4.9 & 0.8 & -4.3 & 0.9 \\
\hline \multirow[t]{2}{*}{ AAS62-32-P51 } & 1 & 98.2 & 1.2 & 0.8 & -4.3 & 0.8 & -4.9 & 0.9 \\
\hline & 2 & 98.5 & 1.6 & 0.7 & -3.8 & 0.8 & -4.6 & 0.9 \\
\hline AAS62-32-P102 & 1 & 98.3 & 1.4 & 0.8 & -4.1 & 0.8 & -4.8 & 0.9 \\
\hline \multirow[t]{3}{*}{ AAS38-207-P42 } & 1 & 83.4 & 2.1 & 0.9 & -2.2 & 1.1 & -3.3 & 1.2 \\
\hline & 2 & 82.2 & 1.9 & 0.9 & -1.8 & 1.1 & -2.8 & 1.2 \\
\hline & 3 & 86.5 & 22.0 & 0.9 & 8.1 & 1.2 & -3.3 & 1.3 \\
\hline \multirow[t]{3}{*}{ AAS38-203-P67 } & 1 & 98.8 & 1.5 & 0.7 & -0.4 & 0.8 & -1.2 & 0.9 \\
\hline & 2 & 98.6 & 1.6 & 0.8 & -0.5 & 0.8 & -1.3 & 0.9 \\
\hline & 3 & 98.6 & 1.6 & 0.7 & -0.5 & 0.8 & -1.4 & 0.9 \\
\hline \multirow[t]{2}{*}{ AAS38-203-P105 } & 1 & 97.7 & -0.6 & 0.7 & -2.2 & 0.8 & -1.9 & 0.9 \\
\hline & 2 & 66.8 & 2.6 & 0.7 & 0.4 & 0.7 & -0.9 & 0.8 \\
\hline \multirow[t]{2}{*}{ AAS62-51-P24 } & 1 & 95.0 & 1.2 & 0.8 & 0.3 & 0.8 & -0.3 & 0.9 \\
\hline & 2 & 95.1 & 1.5 & 0.8 & 0.3 & 0.8 & -0.5 & 0.9 \\
\hline AAS38-187-P23 & 1 & 53.1 & -1.4 & 0.6 & -10.6 & 0.8 & -9.9 & 0.8 \\
\hline AAS38-169-P59 & 1 & 74.5 & 3.5 & 0.6 & 7.6 & 0.7 & 5.7 & 0.7 \\
\hline \multicolumn{9}{|l|}{ 3) Porphyritic } \\
\hline AAS62-61-P42 & 1 & 96.6 & -3.0 & 0.9 & -11.3 & 1.3 & -9.7 & 1.3 \\
\hline
\end{tabular}




\begin{tabular}{|c|c|c|c|c|c|c|c|c|}
\hline AAS62-61-P63 & 1 & 68.1 & 7.3 & 0.8 & -3.2 & 1.3 & -7.0 & 1.3 \\
\hline \multirow[t]{4}{*}{ AAS62-61-P107 } & 1 & 78.4 & 29.5 & 0.9 & 11.2 & 1.2 & -4.2 & 1.3 \\
\hline & 2 & 98.8 & 4.1 & 1.1 & -2.8 & 1.3 & -4.9 & 1.4 \\
\hline & 4 & 69.4 & 27.9 & 1.0 & 10.4 & 1.4 & -4.1 & 1.5 \\
\hline & 5 & 62.6 & 29.0 & 0.8 & 11.7 & 1.2 & -3.4 & 1.3 \\
\hline AAS62-61-P108 & 1 & 81.5 & 20.3 & 0.9 & 8.2 & 1.3 & -2.3 & 1.3 \\
\hline \multirow[t]{3}{*}{ AAS38-164-P26 } & 1 & 79.0 & 28.7 & 0.8 & 10.3 & 1.2 & -4.6 & 1.3 \\
\hline & 2 & 84.7 & 3.8 & 0.9 & -2.8 & 1.2 & -4.8 & 1.3 \\
\hline & 3 & 70.5 & 30.5 & 0.8 & 11.0 & 1.2 & -4.9 & 1.3 \\
\hline \multirow[t]{2}{*}{ AAS38-164-P27 } & 1 & 98.5 & -9.3 & 0.9 & -12.5 & 1.3 & -7.7 & 1.4 \\
\hline & 2 & 82.4 & 23.3 & 0.8 & 7.9 & 1.3 & -4.2 & 1.3 \\
\hline \multirow[t]{2}{*}{ AAS38-164-P31 } & 1 & 98.3 & 19.3 & 1.3 & 5.1 & 1.3 & -5.0 & 1.5 \\
\hline & 2 & 67.9 & 6.2 & 0.9 & -1.8 & 1.3 & -5.0 & 1.4 \\
\hline \multirow[t]{2}{*}{ AAS38-164-P48 } & 1 & 81.8 & 24.8 & 0.9 & 10.3 & 1.4 & -2.6 & 1.4 \\
\hline & 2 & 79.2 & 31.3 & 0.9 & 13.9 & 1.3 & -2.4 & 1.3 \\
\hline \multirow[t]{2}{*}{ AAS38-188-P13 } & 1 & 97.4 & 5.3 & 1.2 & -2.6 & 1.6 & -5.3 & 1.7 \\
\hline & 2 & 66.9 & 25.6 & 1.0 & 8.8 & 1.6 & -4.6 & 1.7 \\
\hline \multirow[t]{2}{*}{ AAS38-188-P64 } & 1 & 90.5 & 9.4 & 1.0 & -0.2 & 1.6 & -5.1 & 1.6 \\
\hline & 2 & 88.7 & 10.5 & 1.0 & 0.5 & 1.6 & -4.9 & 1.7 \\
\hline AAS38-204-P65 & 2 & 98.6 & 8.5 & 1.2 & 2.9 & 0.9 & -1.5 & 1.1 \\
\hline \multirow[t]{2}{*}{ AAS38-204-P76 } & 1 & 89.7 & 26.6 & 1.2 & 11.7 & 0.9 & -2.1 & 1.1 \\
\hline & 2 & 89.6 & 21.0 & 2.0 & 10.3 & 1.2 & -0.6 & 1.6 \\
\hline AAS38-204-P43 & 1 & 94.2 & 15.1 & 1.2 & 6.0 & 0.9 & -1.8 & 1.1 \\
\hline \multirow[t]{2}{*}{ AAS38-204-P16 } & 1 & 83.6 & 13.7 & 1.2 & 7.1 & 0.9 & -0.1 & 1.1 \\
\hline & 2 & 82.1 & -0.8 & 1.5 & 0.8 & 0.9 & 1.2 & 1.2 \\
\hline \multirow[t]{2}{*}{ AAS38-167-P1 } & 1 & 98.6 & 9.4 & 1.0 & 0.3 & 1.1 & -4.6 & 1.2 \\
\hline & 2 & 79.5 & 25.4 & 1.1 & 9.8 & 1.0 & -3.4 & 1.2 \\
\hline \multirow[t]{2}{*}{ AAS38-167-P5 } & 1 & 81.2 & 23.4 & 0.8 & 9.0 & 1.0 & -3.2 & 1.0 \\
\hline & 2 & 78.8 & 24.8 & 0.8 & 9.6 & 0.9 & -3.3 & 1.0 \\
\hline \multirow[t]{2}{*}{ AAS38-167-P16 } & 1 & 69.0 & 25.0 & 0.9 & 11.2 & 1.0 & -1.8 & 1.1 \\
\hline & 2 & 58.0 & 23.2 & 0.8 & 10.1 & 0.9 & -2.0 & 1.0 \\
\hline AAS38-167-P20 & 1 & 95.9 & 9.4 & 0.9 & 2.3 & 1.0 & -2.6 & 1.1 \\
\hline \multirow[t]{3}{*}{ AAS38-167-P79 } & 1 & 96.3 & -1.6 & 0.9 & -3.4 & 1.0 & -2.5 & 1.1 \\
\hline & 2 & 96.7 & 4.5 & 0.9 & 0.1 & 1.0 & -2.2 & 1.1 \\
\hline & 3 & 96.2 & 23.6 & 0.9 & 10.7 & 1.0 & -1.5 & 1.1 \\
\hline \multirow[t]{3}{*}{ AAS62-32-P4 } & 1 & 78.9 & 14.6 & 0.7 & 4.7 & 0.8 & -2.9 & 0.9 \\
\hline & 2 & 96.6 & 9.3 & 0.7 & 0.6 & 0.8 & -4.3 & 0.9 \\
\hline & 3 & 91.8 & 5.0 & 1.0 & 0.0 & 0.9 & -2.6 & 1.1 \\
\hline \multirow[t]{2}{*}{ AAS62-32-P15 } & 1 & 74.7 & 23.3 & 0.7 & 9.1 & 0.8 & -3.0 & 0.9 \\
\hline & 2 & 79.4 & 22.9 & 0.8 & 8.9 & 0.8 & -3.0 & 0.9 \\
\hline \multirow[t]{2}{*}{ AAS62-32-P17 } & 1 & 75.1 & 23.3 & 1.1 & 10.4 & 0.8 & -1.8 & 1.0 \\
\hline & 2 & 75.6 & 31.2 & 0.6 & 13.6 & 0.8 & -2.6 & 0.9 \\
\hline AAS62-32-P18 & 1 & 88.5 & 39.7 & 0.7 & 22.2 & 0.8 & 1.6 & 0.9 \\
\hline
\end{tabular}




\begin{tabular}{lrrrrrrrr} 
& 2 & 77.1 & 36.8 & 0.7 & 20.4 & 0.8 & 1.2 & 0.8 \\
AAS38-207-P45 & 1 & 75.3 & 29.3 & 0.9 & 12.4 & 1.1 & -2.8 & 1.2 \\
AAS62-9-P20 & 1 & 96.6 & -1.1 & 0.8 & -4.3 & 1.0 & -3.7 & 1.1 \\
& 2 & 93.7 & 14.4 & 0.8 & 5.3 & 1.0 & -2.2 & 1.1 \\
AAS62-9-P44 & 1 & 98.8 & -5.5 & 0.8 & -7.8 & 1.0 & -4.9 & 1.1 \\
& 2 & 99.1 & -2.1 & 0.9 & -12.1 & 1.1 & -11.0 & 1.2 \\
AAS62-9-P62 & 1 & 98.4 & 18.5 & 0.8 & 7.9 & 1.0 & -1.8 & 1.1 \\
& 2 & 75.7 & 23.6 & 0.8 & 10.5 & 1.0 & -1.7 & 1.1 \\
AAS38-203-P49 & 1 & 93.6 & 10.2 & 0.8 & 2.5 & 0.9 & -2.8 & 1.0 \\
& 2 & 66.0 & 16.1 & 0.8 & 5.5 & 0.8 & -2.9 & 0.9 \\
AAS62-51-P11 & 1 & 98.4 & 6.7 & 0.8 & 0.1 & 0.8 & -3.4 & 0.9 \\
AAS62-51-P13 & 1 & 98.2 & -3.7 & 0.8 & -5.9 & 0.8 & -4.0 & 0.9 \\
& 2 & 98.6 & 1.2 & 0.8 & 1.6 & 0.8 & 1.0 & 0.9 \\
AAS62-51-P72 & 1 & 99.0 & -6.6 & 0.8 & -8.1 & 0.7 & -4.7 & 0.9 \\
AAS62-51-P89 & 1 & 98.5 & -2.2 & 0.8 & -5.6 & 0.9 & -4.4 & 1.0 \\
AAS62-51-P96 & 1 & 99.1 & -6.0 & 0.8 & -8 & 0.9 & -4.9 & 0.9 \\
AAS62-40-P149 & 1 & 98.5 & 9.2 & 0.9 & 3.2 & 0.8 & -1.6 & 0.9 \\
AAS38-43-P58 & 1 & 78.8 & 2.8 & 0.5 & -0.5 & 0.6 & -2.0 & 0.7 \\
4) Barred & & & & & & & & \\
AAS38-203-P13 & 1 & 79.9 & 29.8 & 0.7 & 11.8 & 0.8 & -3.6 & 0.9 \\
AAS38-187-P4 & 1 & 63.4 & 21.0 & 0.6 & 6.0 & 0.6 & -4.9 & 0.7 \\
& 2 & 68.0 & 26.5 & 0.6 & 6.6 & 0.7 & -7.2 & 0.8 \\
\hline
\end{tabular}

732

733

734

735

736

737

738

739 